\title{
SOBRE EL CONTRACTUALISMO. CONSECUENCIAS POLÍTICAS Y JURÍDICAS (I)
}

\author{
Juan Fernando Segovia \\ CONICET, Facultad de Ciencias Jurídicas y Sociales, \\ Universidad de Mendoza, Mendoza, Argentina \\ Contacto:segojuan@gmail.com
}

Recibido: 2 de febrero de 2021

Aprobado: 31 de marzo de 2021

Para citar este artículo:

Segovia, J. F. (2021). "Sobre el contractualismo. Consecuencias políticas y jurídicas”. Prudentia Iuris, N. 91, pp. 203-221

DOI: https://doi.org/10.46553/prudentia.91.2021.pp.203-221

Resumen: El presente trabajo pretende esclarecer algunas de las consecuencias que el contractualismo trae al Derecho y la política (virtualidad, voluntarismo, anarquía, positivismo, estatismo, etc.), valiéndose de un examen del estado de naturaleza y del significado del contrato social. Se ha elaborado en base a fuentes y consultando la bibliografía especial.

Palabras clave: Contractualismo, Estado de naturaleza, Contrato social, Orden jurídico-político, Consentimiento, Constitucionalismo. 


\title{
On Contractualism. Political and Legal Aftermaths (I)
}

\begin{abstract}
This work aims to clarify some legal and political aftermaths of contractualism (virtuality, voluntarism, anarchy, positivism, statism, etc.), appealing to an examen of the state of nature and the meaning of the social contract. It has been prepared based on sources and consulting the special literature.
\end{abstract}

Keywords: Contractualism, State of nature, Social contract, Legal and political order, Consent, Constitutionalism.

\section{Sul contrattualismo.} Conseguenze politiche e legali (I)

Sommario: Questo lavoro si propone di chiarire alcune conseguenze legali e politiche del contrattualismo (virtualità, volontarismo, anarchia, positivismo, statalismo, ecc.), Facendo appello a un esame dello stato di natura e del significato del contratto sociale. È stato preparato sulla base di fonti e consultando la letteratura speciale.

Parole chiave: Contrattualismo, Stato di natura, Contratto sociale, Ordinamento giuridico e político, Consenso, Costituzionalismo.

\section{Introducción}

El trabajo que aquí se presenta es un avance de la investigación acerca de "Naturaleza, libertad y democracia. La natural condición democrática de la humanidad: libertad original, estado de naturaleza, contractualismo y democracia", que estoy desarrollando en el CONICET ${ }^{1}$. Dos cosas deben

1 Mi reconocimiento al CONICET que aprobó el proyecto y financia la investigación, lo 
señalarse. La primera, que, como se advierte por el epígrafe del trabajo y el título del proyecto de investigación, lo que se expondrá no es más que una parte de una tarea más ambiciosa.

En segundo término, más allá de los nombres de uno y otro, resultará conveniente una breve explicación de las razones que me llevan a indagar la trama del problema. Durante años me he encontrado merodeando el mismo tema que puede decirse es el punto de partida de la teoría política moderna, una reflexión acerca de la condición o estado original de la humanidad, sintetizada en una frase repetida en constituciones, libros y declaraciones de derechos: "Todos los hombres son libres e iguales por naturaleza", nacemos todos en libertad e igualdad. Esta premisa condiciona el despliegue posterior de la totalidad de la teoría política en la Modernidad. De la libre e igual condición natural se sigue que nadie tiene por naturaleza el derecho a gobernar a los hombres, que la autoridad política y las instituciones de gobierno surgen no de la naturaleza sino por convención, que en la situación contractual o convencional de la vida política se debe respetar y garantir aquella condición primaria de los hombres: la libertad e igualdad naturales, que tras el contrato social serán políticas.

Los elementos que configuran el pensamiento político moderno hasta nuestros días están claramente entrelazados: estado de naturaleza - contractualismo político - democracia; o, si se quiere: libertad natural - libertad política. "El derecho de naturaleza inspira el derecho político, que impide que las cualidades naturales se vean amenazadas en la práctica de la vida", escribió con gran tino Paul Hazard ${ }^{2}$. Si bien hay una natural conexión entre los extremos (que podrían considerarse causa y efecto), es realmente raro encontrar ese vínculo tanto en los estudios históricos como en los jurídicopolíticos y constitucionales. Al menos, no está esa relación reconocida de modo expreso.

En lo que sigue, quiero mostrar esa vinculación y extraer algunas consecuencias para la teoría política y el Derecho, particularmente el Público.

\section{La virtualidad del orden político-jurídico moderno}

Hace ya un tiempo, en un libro que pasó casi inadvertido, Francesco Gentile demostró que el ordenamiento jurídico de la Modernidad era virtual, pues antes de la decisión que establece el Derecho sólo hay caos, des-

\footnotetext{
mismo que al Instituto de Ciencias Humanas, Sociales y Ambientales (INCIHUSA), del Centro Científico Tecnológico Mendoza, en el que tengo mi lugar de trabajo institucional.

2 Hazard, P. (1988). La crisis de la conciencia europea (1680-1715). Madrid. Alianza, 234.
} 
orden, anarquía, que se convierten en un orden por la decisión de aquel que sanciona el Derecho. Es un orden decisionista, virtual, nunca real; y antinatural, porque supone la enemistad humana y no la natural amistad, ni la sociabilidad como virtud. El supuesto que subyace a esta virtualidad es el estado de naturaleza al que los hombres retornaríamos de desaparecer el Estado y el Derecho; estado de naturaleza que, sea por lo que fuere, siempre se convierte en un estado de guerra. Por tanto, si se quitara el Derecho (la ley en sentido moderno) o se aniquilara el Estado, volveríamos a la primitiva ley de la selva. Tal la premisa que legitima la vis coercitiva del ordenamiento jurídico-político de la Modernidad ${ }^{3}$.

¿De dónde procede esta abstrusa idea, que repiten juristas de la talla de Hans Kelsen y Santi Romano? Evidentemente, proviene de una concepción pesimista de la naturaleza humana, de una maldad natural intrínseca a las personas, que, en la Modernidad, reconoce paternidad en el protestantismo. D. Castellano ha señalado que las doctrinas modernas de la política y del Derecho Público dependen del protestantismo, son constructivistas ${ }^{4}$. Hay en esta afirmación dos extremos que es preciso aclarar.

\section{a. Protestantismo y constructivismo}

El primero es de fácil constatación, pues remite a la antropología luterana, la idea gnóstica del hombre acabado por el pecado, convertido en un itinerante miserable (no un bienaventurado peregrino), a quien ni tan siquiera la gracia divina lo mejora: ésta se solapa al hombre pecador y, sin cambiarlo, lo salva por la sola fe que el hombre recibe sólo por Cristo y de Él. Esta antropología es el fundamento de la virtualidad del orden político y jurídico moderno ${ }^{5}$ y de la ficción del estado de naturaleza que los teóricos pergeñaron. El Estado y la ley modernos son necesarios a causa de la naturaleza pecaminosa de los hombres, medios pensados para reprimir las naturales tendencias anárquicas y disolventes ${ }^{6}$.

El otro extremo es el constructivismo. Tomemos las palabras de Nicola Matteucci, para quien el estado de naturaleza es una "hipótesis

3 Gentile, F. (2001). El ordenamiento jurídico, entre la virtualidad y la realidad. Madrid. Marcial Pons.

4 Castellano, D. (2020). Introducción a la filosofía de la política. Breve manual. Madrid. Marcial Pons, 15-16.

5 Castellano, D. (2016). Martín Lutero. El canto del gallo de la Modernidad. Madrid. Marcial Pons. Segovia, J. F. (2016). "Lutero y los orígenes religiosos de la secularización". En Ayuso, M. (Ed.). Consecuencias político-jurídicas del protestantismo. A los 500 años de Lutero. Madrid. Marcial Pons, 49-84.

6 Cuando más adelante considere el contrato social, se verá cuán cierto es. 
lógica negativa sobre cómo sería el hombre fuera de un contexto social y político, a fin de establecer las premisas para el real funcionamiento del poder político"7. Para comprender su significado, conviene invertir los términos: el Estado (el poder político) garantiza la seguridad, la paz, el respeto de los derechos; si quitáramos el Estado, retrotraeríamos a la condición natural en la que la seguridad, la paz y el respeto de los derechos eran imposibles ${ }^{8}$.

El consenso, del cual el pacto o contrato es una modalidad, es el concepto que expone en términos políticos la constructivista gnoseología moderna. En efecto, Hobbes afirmó que el hombre sólo conoce con certeza lo que el hombre hace por sí mismo ${ }^{9}$. Tal idea tiene, de fondo, la impotencia de la razón moderna para conocer lo que las cosas son (los nominalistas, Descartes, Kant), y la reducción de la razón a la habilidad para construir reglas del hacer, para calcular las partes de una estructura que, articuladas en su conjunto, sirven al fin que la razón se propuso (nuevamente Hobbes) ${ }^{10}$. La razón que construye el mecanismo político (Commonwealth), al establecer arbitrariamente el fin al que debe servir, delimita primariamente separando los espacios públicos de los ambientes privados, abiertos aquéllos, cerrados éstos ${ }^{11}$.

Así procede el constructivismo moderno: si en el estado de naturaleza las relaciones humanas son o se han convertido en relaciones de fuerza ilegítima, violatorias de la igualdad y libertad naturales, la solución está en convertir esa dominación ilegítima en un poder legítimo fundándolo en "el consenso" que crea el Estado (pactum societatis) y establece su forma de gobierno (pactum subiectionis) ${ }^{12}$. Pero la fuerza no desaparece, las cadenas no

7 Matteucci, N. (2010). “Contractualismo”. En Matteucci, N. El Estado moderno. Léxico y exploraciones. Madrid. Unión Editorial - Universidad Francisco Marroquín, 111.

8 La excepción podría decirse que está en el marxismo: el aparato represivo estatal encubre la explotación del hombre por el hombre, el hombre alienado de sí, de los demás y de la naturaleza. Solución: llevado a su extremo absoluto el dominio estatal por la dictadura del proletariado, el Estado desaparecerá, dando paso a una comunidad libre de hombres reconciliados consigo mismo y con la naturaleza. La funesta lógica moderna llevada al absurdo.

9 Hobbes, Th. (1642). "De cive". En Hobbes, Th. The works of Thomas Hobbes. II. London. John Bohn, XVIII.

10 Gillespie, M. A. (2008). The theological origins of modernity. Chicago \& London. The University of Chicago Press, 231. "La ciencia, como Hobbes la entiende, hará posible que los seres humanos sobrevivan y prosperen en el caótico y peligroso mundo del Dios nominalista. Esta ciencia no busca el conocimiento de lo qué es, sino de cómo funcionan las cosas, es decir, cómo son o se las puede hacer o se puede impedir que sean. Tal conocimiento es un artificio, esto es, el conocimiento técnico o mecánico [...]”.

11 Walzer, M. (1984). "Liberalism and the art of separation". Political Theory Nro. 12/3, 315-330.

12 La necesidad de los dos extremos fue expuesta por Gierke, O. (1950). Natural law 
se rompen, se transforman en consentidas y, por ello, legítimas, tolerables. Sólo el Estado que persigue su propia autoconservación puede garantizar la conservación a los individuos que están bajo su dominio. La capacidad de discernir la extensión de lo público compete al Estado, pues lo público es el bien o interés del Estado, todo lo que atañe a su autoconservación. Porque si la máquina deja de funcionar, vuelve el caos, el desorden y la guerra de las dislocadas piezas mecánicas entre sí.

\section{b. Constructivismo y virtualidad}

D. Castellano, en el pasaje citado que ha dado pie a estas digresiones, afirmaba también que el constructivismo protestante está en la base de la teoría política y el Derecho Público modernos. No es difícil comprobarlo. Lo privado, separado de lo público, especifica los sitios o dominios del individuo o de la sociedad, que son libres en tanto cuanto no tienen incidencia en la autoconservación del Estado. Si se quiere, es el dominio de los derechos, de los intereses particulares o de los bienes privados, comenzando por la libre conciencia. Lo que significa que todo aquello que no es del Estado y que no lo afecta, puede caber en los módulos privados.

El constitucionalismo funciona con esta premisa, el arte de la separación: una parte del texto constitucional se dedica a las libertades, los derechos y las garantías; otra, generalmente la más extensa (a veces, la única), se detiene en los poderes del Estado, sus funciones y competencias. En este espacio, el poder; en aquél, la obediencia premiada con libertades que no causen daño al poder ${ }^{13}$. Por eso, en palabras de Matteucci, el pacto es "la condición formal de la existencia jurídica del Estado"14, se entienda por pacto ya la constitución moderna, ya el pacto en el que ésta se funda y que ella expresa. Cuando Michael P. Zuckert rastrea las ideas que se expresan en la Declaración de la Independencia de los Estados Unidos de 1776 (el gobierno como artificio, el consentimiento como medio de instituir y controlar el poder político legítimo, la igualdad natural y el derecho originario a la revolución), no puede menos que destacar de qué manera el pensamiento moder-

and the theory of society: 1500 to 1800. Cambridge. Cambridge University Press, 33-61, 137-161.

13 Los constitucionalistas dicen que no es lo mismo "reconocer" libertades (por ser antecedentes a la constitución) que "concederlas". Si bien la distinción es justificada a nivel teórico/ ideológico, carece de toda relevancia práctica/judicial. Los derechos son exigibles y justiciables en tanto positivos, se digan reconocidos o concedidos.

14 Matteucci, N. (2010). "Contractualismo". Ob. cit., 125. 
no está en los antípodas de las observaciones aristotélicas. Según Zuckert: "Sólo una creación racional, no un crecimiento natural, puede producir un gobierno justo o bueno. Por lo tanto, el gobierno debe ser un artificio humano. Si artificio, entonces debe haber una situación (teórica) prepolítica en la que surge lo político y fuera de ella. Así, la idea del gobierno como artificio está también subordinada en última instancia al compromiso de asegurar los derechos"15.

Volvamos ahora a Gentile. Si el ordenamiento jurídico moderno es virtual se debe a que el criterio del ordenamiento, la idea que preside el orden, proviene de un proceso externo a la normación, es decir, artificial; de esta clase es la teoría de la Grundnorm o norma fundamental de Kelsen, que se origina en el criterio formulado por el operador jurídico, el constituyente, criterio propuesto y no puesto o dado, arbitrario, porque depende del querer del operador. El ordenamiento jurídico se convierte en un sistema de "representaciones convencionales de normas, elaboradas por la ciencia jurídica sobre la base del presupuesto de la norma fundamental"; no es un orden real sino virtual, esto es, un orden normativo que carece de correspondencia con el orden real, resultado de una operación de sistematización puramente hipotético-deductiva ${ }^{16}$. El ordenamiento jurídico es un constructo geométrico dependiente de la mente de su hacedor, como había propuesto Hobbes.

El presupuesto común a todos estos geómetras del Derecho y la política, de Hobbes a Rousseau y de Locke a Rawls, es que las relaciones interindividuales son caóticas, el estado natural del hombre es el conflicto nacido del egoísmo. He aquí la flagrante contradicción de esta escuela, que consiste en pretender instituir un orden -virtual-partiendo de un no orden objetivo, real; así en Derecho como en política ${ }^{17}$.

\section{Acerca del estado de naturaleza}

\section{a. Naturaleza, libertad e igualdad}

Lo que permite construir virtualmente un ordenamiento político-jurídico, el Estado de Derecho moderno, es el punto de partida consistente en la ficción de un estado de naturaleza en el que reina la enemistad, más o

15 Zuckert, M. P. (1994). Natural rights and the new republicanism. Princeton. Princeton University Press, 13.

16 Gentile, F. (2001). El ordenamiento jurídico, entre la virtualidad y la realidad. Ob. cit., 17-19.

17 Cfr. Gentile, F. (1983). Intelligenza politica e ragion di Stato. Milano. Giuffrè. Castellano, D. (1993). La razionalità della politica. Napoli. Edizioni Scientifiche Italiane, 67-82. 
menos gravosa, entre los hombres, pero que siempre hace imposible la vida en tal condición. En los contractualistas modernos la idea de dominio es extraña al estado de naturaleza, porque el poder de un hombre sobre otro conlleva la esclavitud o servidumbre de quien es sometido, lo que repugna a la condición naturalmente libre de todo ser humano. Ya Grotius lo sostiene: nadie es esclavo por naturaleza, la esclavitud es contraria a la condición natural ${ }^{18}$, de donde se deduce, como hizo Pufendorf, la igualdad de los hombres ${ }^{19}$. Locke recogerá ambos argumentos: en el estado de naturaleza los hombres son libres e iguales y nadie puede someterse por contrato a la esclavitud de otro ni sujetarse a un poder arbitrario ${ }^{20}$. Arbitrario se dice del poder no consentido por el sujeto sobre el que se ejerce. El poder, todo poder, en dicho estado natural, se entiende como coerción sobre la libertad humana, una negación de la naturaleza libre e igual de los hombres. Y si existe tal dominio en el estado de naturaleza es siempre considerado ilegítimo. Es así como el contractualismo pretende preservar la igualdad natural de los hombres pues nadie está autorizado a regir sobre los demás, porque la autoridad no es natural ${ }^{21}$.

Los modernos contractualistas, cualquiera sea su versión del estado de naturaleza, parten de la premisa de la ilegitimidad del poder o dominio en la condición natural del hombre, de modo que todo poder de un hombre sobre otro u otros es antinatural pues hace del subordinado un siervo, contraría su libertad natural. Parecería así repetirse la versión atribuida a San Agustín, cuando escribió: "Rationalem factum ad imaginem suam noluit nisi irrationabilibus dominari: non hominem homini, sed hominem pecori". Esto es, quiso Dios que el hombre racional, hecho a su imagen, dominara solamente a los irracionales, no el hombre al hombre, sino el hombre al ganado. Continúa San Agustín: "Prima ergo servitutis causa peccatum est; ut homo homini conditionis vinculo subderetur [...]", es decir, la causa primera de la servidumbre es, pues, el pecado, que somete un hombre a

18 Grotius, H. (1625). The rights of war and peace. Indianapolis. Liberty Fund, III, 7, 1).

19 Pufendorf, F. (1672). Le droit de la nature et des gens. Amsterdam, III, 2, 8. La igualdad consiste en la privación de toda relación, el aislamiento de los individuos que los hace independientes, autónomos. Escribe Pufendorf, F. (1672). Le droit de la nature et des gens, cit. I, 1: "El Estado de naturaleza es aquel que acompaña al hombre desde el momento de su nacimiento, independientemente de toda voluntad humana y por un puro efecto de la institución divina", pues los hombres no están en relación unos con otros, como no sea por "el vínculo simple y universal de la semejanza de su naturaleza con independencia de todo acto humano y de toda convención que los sujete a los otros de un modo particular".

20 Locke, J. (1689). Two treatises of government. London, II, IV, 23.

21 Zuckert, M. P. (1994). Natural rights and the new republicanism. Ob. cit., 9. Riley, P. (1982). Will and political legitimacy. A critical exposition of social contract theory in Hobbes, Locke, Rousseau, Kant, and Hegel. Cambridge. Harvard University Press, x. 
otro con el vínculo de subordinación ${ }^{22}$. En la versión contractualista, sin embargo, hay una notable omisión, la del pecado original. En efecto, lo que en Agustín significa el pecado original es desplazado (o reemplazado) por el pacto; la naturaleza caída del hombre (que lo convierte en peregrino y sujeto al poder humano) es reemplazada (o desplazada) por la idea de la libre voluntad, que hace del consenso/consentimiento el motivo de la sujeción humana ${ }^{23}$.

Cuando los contractualistas se refieren a la libertad natural como condición humana, no tratan de la libertad en sentido moral sino en su alcance jurídico y político, es decir, una facultad entendida ya como Derecho Subjetivo ${ }^{24}$ : ser libre en el estado de naturaleza es no estar sometido a la voluntad/ley de otro, no sólo negativamente (no somos siervos, tampoco esclavos ni dominados) sino positivamente: tenemos el derecho de actuar conforme a nuestra voluntad. De aquí que el voluntarismo moderno nada tiene que ver con la doctrina clásica de la obediencia ${ }^{25}$. Se basa en la autodeterminación.

Para ilustrarlo tomo un caso ejemplar ${ }^{26}$. En Locke, el estado de la naturaleza es un elemento ajeno a la revelación bíblica. El paso del estado de inocencia a la condición después de la caída es muy diferente del paso del estado de la naturaleza al estado civil, como advirtió tiempo ha Leo Strauss, pues ni el castigo de la caída, ni la transgresión de Eva, influyen en su doctrina política ${ }^{27}$. Me atrevo a decir que el estado de naturaleza lockeano se parece más a la vida peregrina después de la caída que al estado

22 San Agustín (426). "La Ciudad de Dios". En San Agustín. Obras. Madrid. BAC, XIX, XV.

23 Sternberger, D. (1992). "La vieja polémica acerca del origen de la dominación". En Sternberger, D. Dominación y acuerdo. Barcelona. Gedisa, 33-34.

24 Brett, A. S. (2011). Changes of state. Nature and the limits of the city in early modern natural law. Princeton \& Oxford. Princeton University Press, 95: "La esclavitud milita contra la esencia misma de la humanidad. El derecho es innato".

25 Riley, P. (1982). Will and political legitimacy. A critical exposition of social contract theory in Hobbes, Locke, Rousseau, Kant, and Hegel. Ob. cit., 3-19, lo estudia especialmente con relación a Aristóteles y Platón, San Agustín y Santo Tomás de Aquino, Ockham, N. de Cusa y F. Suárez, concluyendo que, aunque las raíces del voluntarismo moderno pueden trazarse desde la escuela católica, aquél saca la voluntad de las esferas de la moral, el pecado y las buenas obras, para emplazarla en el fundamento de toda legitimidad social.

26 Ejemplar, digo, porque hay intérpretes que ligan el estado de naturaleza lockeano a la teología cristiana, si bien protestante. Cfr. Dunn, J. (1969). The political thought of John Locke. Cambridge. Cambridge University Press, cap. 9. La crítica en Segovia, J. F. (2014). La ley natural en la telaraña de la razón. Ética, derecho y política en John Locke. Madrid. Marcial Pons, 137-146.

27 Strauss, L. (1953). Natural right and history. Chicago. University of Chicago Press, 215-216. 
de inocencia bíblico, en un todo de acuerdo con la antropología teológica protestante. Porque hay un elemento que Locke subraya: la inseguridad que proviene de la falta de certeza, por el permanente contraste entre la tendencia a vivir pacífica y laboriosamente y el deseo natural de la felicidad personal, de modo tal que el hombre sólo puede ser feliz si es capaz de desarrollar su individualidad aun contra el provecho que obtiene del vivir con otros ${ }^{28}$.

\section{b. Estado de naturaleza y contractualismo}

El contractualismo típicamente moderno solamente cobra forma cuando el contrato social se idealiza como método de salida de una condición primigenia de los hombres, también idealizada, que impide llevar una vida humana, que se conoce con el nombre de estado de naturaleza. No es la vida buena la que resulta imposible en éste, es la vida a secas. En su clásico estudio lo ha reiterado Leo Strauss: "[...] el Estado es un cuerpo artificial nacido de una convención que viene a remediar los problemas del estado de naturaleza"29. Sociedad civil o Estado, y estado de naturaleza, son conceptos antitéticos, están en oposición y uno repele al otro. Lo natural está en contradicción con lo artificial/convencional.

El contractualismo moderno se perfecciona cuando, a las ideas del origen voluntario del gobierno y del poder originario de los individuos o la sociedad (genéricamente, la soberanía), se añade la de un estado natural, esto es, esa condición en la que "los individuos en un estado de naturaleza se reúnen para crear los artefactos de la sociedad y el gobierno"30. Es necesario al contractualismo que el Estado o la sociedad civil se consideren un artificio creado por la voluntad humana y no originado en la naturaleza. Pues si viniera de la naturaleza consagraría una dominación injusta. Esta es la función esencial del estado de naturaleza: exponer la génesis del Es-

28 Simmons, A. J. (1995). On the edge of anarchy. Locke, consent, and the limits of society. Princeton. Princeton University Press, 26.

29 Strauss, L. (1953). Natural right and history, Ob. cit., 254.

$30 \mathrm{Kahn}, \mathrm{V}$. A. (2004). Wayward contracts. The crisis of political obligation in England, 1640-1674. Princeton \& Oxford. Princeton U.P., 10. Sin embargo, algunos estudiosos entienden que no es necesario recurrir a la ficción o mito del estado de naturaleza. Lamprecht, en un crítico examen de Hobbes, afirma que el estado de la naturaleza no es histórico sino analítico, no es más que una imagen del hombre como tal vez nunca se encuentra o encontrará. Lamprecht, S. P. (1940). "Hobbes and Hobbism". American Political Science Review Nro. 34/1, 31-53. Podríamos seguir con las objeciones, que no modifican en el fondo la cuestión: sea una necesidad histórica o metodológica, sea una creencia o una táctica, lo cierto es que los contractualistas sostienen ese estado de naturaleza como previo al Estado. 
tado y de su poder de obligar a los individuos. Y es también la función de la voluntad: establecer una cadena causal entre el origen y la conclusión (el efecto), entre la libertad natural y la obediencia al poder secular o religioso (la libertad civil) ${ }^{31}$.

El estado de naturaleza es parte de la narrativa del contractualismo ${ }^{32}$, claro que sí. Pero no es solamente una parte importante del relato, un engranaje de la historia, porque el contractualista es más que un género literario, es una teoría sobre el fundamento de la legitimidad del Estado. Cierto es que la construcción del estado de naturaleza sirve para mostrar la conveniencia del Estado; pero tiene también otra función: demarcar un ámbito de poderes, libertades o derechos, que no se pueden alienar, esto es, las ventajas que siendo naturales al hombre no pueden serles quitadas por el Estado, porque son las que lo constituyen como tal, especialmente la libertad y la igualdad, si bien amenazadas y siempre en riesgo. Si no hubiera "algo" de libertad en la condición natural de los hombres no habría modo de preservarla en la vida política; si la libertad no estuviera amenazada en el estado de naturaleza no tendría sentido resguardarla en la sociedad civil; si el hombre no tuviera cierta libertad el pacto no sería posible, no habría modo de realizarlo ${ }^{33}$.

El contrato como instrumento mediador entre el estado de naturaleza y el Estado es una suerte de reaseguro contra la tiranía, las cadenas ilegítimas. Lo es de por sí, desde que el Estado se pacta y construye como artefacto de seguridad o de pacificación ${ }^{34}$. Pero lo es también por una doble razón que está, algunas veces, implícita: de una parte, el estado de naturaleza es

31 Poder religioso también, por la divulgación entre las sectas protestantes de la naturaleza voluntaria de sus iglesias, instituidas por el consenso o acuerdo de los fieles, no divinamente. Así está tanto en Lutero como en Calvino, cuyos seguidores repetirán coherentemente. Por caso, Roger Williams escribió: “[...] la iglesia, o la compañía de fieles, sea verdadera o falsa, es semejante a un cuerpo o colegio de médicos en una ciudad, a una corporación, sociedad o la compañía de la India Oriental o de comerciantes de Turquía, o a cualquier sociedad o empresa en Londres [...]". Williams, R. (1644). The Bloudy Tenent, Of Persecution, For Cause of Conscience. London. J. Haddon, 46-47.

32 Dicus, A. (2015). “'Some man' and the savage”. Prose Studies Nro. 37/2, 97-111.

33 Caro, J. (2011). The origins of free people. New York \& London. Continuum, 10 y 110 : "Debe haber una pizca, un indicio, un mito, una creencia o una intuición de la libertad que vendrá para que lo que la amenaza pueda ser percibido y registrado como una amenaza para nuestra libertad". Entonces, "la proto-libertad, por lo tanto, siempre requiere una cuidadosa, perfecta modulación".

34 Pufendorf, S. (1673). On the Duty of Man and Citizen According to Natural Law. Cambridge. Cambridge University Press, II, 6. 1: "Es evidente, en primer lugar, que el individuo encuentra en otros hombres, más que en las fortificaciones, las armas o los animales estúpidos, una defensa más útil y eficaz contra los males que la depravación humana amenaza con infligirle; y como el poder de un hombre es limitado en extensión, fue necesario que se combinara con otros hombres para lograr ese fin". 
irrepetible en su condición injusta, esto es, se sale de él para solucionar la injusticia (inseguridad, tiranía, ilegitimidad, etc.); no es una edad de oro, aunque pudo haberlo sido; no es un ideal al que volver, aunque contenga elementos ideales. De otra parte, porque lo retenido por los individuos, sus derechos y libertades, permite la resistencia al tirano, es decir, la libertad remanente (que ahora se goza en la sociedad civil) puede activar la desobediencia al gobierno que se hace injusto, tiránico, arbitrario, despótico ${ }^{35}$. Se puede considerar como paradigmática la Declaración de la Independencia redactada por Jefferson y la afirmación de que todas estas son "verdades evidentes".

\section{c. Naturaleza y pasiones}

De esta índole antitética (una realidad alternativa hipotética, enfrentada a un orden coercitivo de garantías, la ilegitimidad de frente a la legitimidad), se concluye que el paso de un estado a otro no se produce "naturalmente", por la fuerza de las cosas, espontáneamente, sino por acuerdos, es decir, a través de actos voluntarios por los que se manifiesta la intención de salir del estado de naturaleza. Razón por la cual el estado civil "no es natural" sino artificial, no es un producto de la cultura sino de la humana voluntad, y no de la naturaleza; su legitimidad no es independiente de la voluntad de los hombres que en él decidan vivir, pues "el principio de legitimidad de la sociedad política es el consenso"36.

Pero la función del estado de naturaleza no se agota en esto, es más que una "construcción mental contrafáctica"; es también una "herramienta heurística", un ensayo de psicología política. Cuando los contractualistas diseñan, cada uno a su manera, el estado de naturaleza, tratan de descubrir cuál es la pasión dominante en los hombres, aquello que dirige o gobierna sus conductas, para así reconstruir la obligación política valiéndose de ese rasgo predominante, que se convertirá en la piedra angular de la sociedad civil ${ }^{37}$. De hecho, en los neocontractualistas, como John Rawls o David Gauthier, se reduce a esto último: el hecho ya no cuenta, el irrealismo se

35 Del derecho de resistencia, anclado en la libertad original en el estado de naturaleza, no podemos tratar acá.

36 Bobbio, N. (1986). "El modelo iusnaturalista". En Bobbio, N. y Bovero, M. Sociedad y Estado en la filosofía moderna. El modelo iusnaturalista y el modelo hegeliano-marxiano. México. FCE, 55.

37 Es, por tanto, algo más que una "hipótesis lógica negativa" sobre la vida del hombre sin Estado, como vimos afirmó N. Matteucci (nota 7); porque esa vida aestatal permite construir el Estado según las tendencias humanas que la condición natural desnuda. 
ha llevado al extremo, sólo valen las tendencias básicas de una psicología política constructivista.

En los primeros contractualistas se decía que ese motor primario de los hombres no era el bien o la virtud sino el "amor propio" (Rousseau), o el "temor a la muerte" (Hobbes), o la "propiedad privada" (Locke), todos nombres que indican la inclinación primaria de los individuos a la "autoconservación" o "propio interés". Las pasiones o intereses podían ser un obstáculo al contrato (como lo eran a la vida silvestre o natural), pero reconducidas correctamente podían convertirse en motivo (causa) del consentimiento individual. La estrategia consistía en convertir el problema en una solución ("una forma de doblegar el entusiasmo político potencialmente subversivo"38), un procedimiento de cálculo que acabará canalizando las pasiones hacia el consentimiento $^{39}$. No es la razón, afirma Hobbes, sino el odio, el temor, la esperanza, el amor o cualquiera otra pasión lo que lleva a los hombres al consentimiento ${ }^{40}$. Todo lo cual está en dependencia de una antropología de corte pesimista y materialista, que construye la sociedad civil sobre tendencias negativas que, contrapuestas, producen el efecto contrario (un orden virtual, el estatal). "El sujeto encarnado en las pasiones y los intereses, de una parte, y la construcción artificial de la obligación [política], de la otra, eran dos caras de la misma moneda" 41.

La economía libidinal de la obligación política cambió decisivamente en el siglo XVII, desde que ya no será el amor al soberano lo que la explique sino el consentimiento basado en la consideración de las pasiones y los intereses del individuo ${ }^{42}$. De tal manera, un vínculo político establecido sobre las pasiones e intereses dominantes, afirma Victoria Kahn, será un vínculo legítimo ("el acto racional de la sujeción voluntaria"), mientras que el que se establezca sobre cualquiera otra base producirá un vínculo ilegítimo ("el acto irracional de la servidumbre voluntaria"43). Más adelante, David Hume

38 Kahn, V. A. (2004). Wayward contracts. The crisis of political obligation in England, 1640-1674. Ob. cit., 18.

39 Ibídem, 13 y 14. El interés, entiende Kahn, es una pasión confiable, de la que nos podemos fiar (aunque sea volátil).

40 Hobbes, Th. (1642). "De cive". Ob. cit., I, 2, 1. Hobbes, Th. (1651). "Leviathan". En Hobbes, Th. The works of Thomas Hobbes. III. London. John Bohn, I, XIII.

41 Kahn, V. A. (2004). Wayward contracts. The crisis of political obligation in England, 1640-1674. Ob. cit., 15.

42 Gunn, J. A. W. (1968). "Interest Will Not Lie: a seventeenth-century political maxim". Journal of the History of Ideas Nro. 29/4, 551-564; y Hirschman, A. O. (1977). Las pasiones y los intereses. México. FCE.

43 Kahn, V. A. (2004). Wayward contracts. The crisis of political obligation in England, 1640-1674. Ob. cit., 58. En este escenario, añade Kahn, "los apetitos naturales del individuo proporcionan el motivo para el consentimiento, y el consentimiento legitima el poder coercitivo del Estado". 
rechazará la tesis contractualista pero reafirmará que la razón es o debe ser esclava de la pasión, asumiendo así la enseñanza hobbesiana ${ }^{44}$. Y ni qué decir de Rousseau y el elogio del amour de soi.

\section{d. Precariedad del estado de naturaleza}

Si seguimos el razonamiento de Leo Strauss, en Derecho Natural e historia (1953), se puede distinguir la enseñanza clásica del iusnaturalismo -que toma al bien humano como fundamento moral de la vida política- de la teoría moderna nacida del convencionalismo iusnaturalista -que entiende superior la condición del estado de naturaleza (salvo Hobbes) a la de la sociedad civil $^{45}$-; distinción expresada en la contradicción entre los deberes naturales y los Derechos Naturales, pues éstos son una reacción contra la teología y se sustentan en el naturalismo de las ciencias modernas recién nacidas ${ }^{46}$.

En la exposición de Strauss, entre la clasicidad y la Modernidad, se produce el paso de la filosofía -anclada en el orden divino- a la ciencia natural, cambio de marcha que es paralelo al tránsito del bien a las libertades, de los deberes a los derechos, de lo social a lo individual. Maquiavelo preparó el camino al moderno Derecho Natural, cuando descartó el estudio los fines de la vida política y se centró en la causa eficiente de ella, que es el conflicto inherente a toda comunidad humana. En consecuencia, la justicia es posterior a la vida política, pues sólo es posible dentro de un orden social establecido, de modo que la conservación y la defensa del orden político no están limitadas por los principios de la justicia. En Maquiavelo está el origen del positivismo jurídico que caracteriza a la Modernidad.

Preguntarse por la causa eficiente es inquirir por el origen que es la fundación de la ciudad, y el origen es siempre un caso extremo, mucho más revelador que los casos normales de las raíces de la sociedad civil. En el origen está la fuerza, las relaciones de fuerza entre los hombres. Y este dato será tomado por los iusnaturalistas del siglo XVII: las bases de la ley natural deben buscarse, afirma Strauss, "no en el fin del hombre, sino en su origen" $"$. De tal modo el iusnaturalismo racionalista desecha por completo

44 Hume, D. (1739). Tratado de la naturaleza humana. Madrid. Tecnos, II, III, III: "La razón es, y sólo debe ser, esclava de las pasiones, y no puede pretender otro oficio que el de servirlas y obedecerlas".

45 Strauss, L. (1953). Natural right and history. Ob. cit., 184.

46 Ibídem, 164 y 186.

47 Strauss, L. (October 1950). "On the spirit of Hobbes' political philosophy". Revue Internationale de Philosophie Nro. 4/14, 415-416. También Strauss, L. (1953). Natural right and history. Ob. cit., 177-180. 
el Derecho Natural de corte aristotélico: lo justo y lo virtuoso no están en el comienzo de la vida política; en éste sólo se encuentra poder o fuerza, la lucha por la autosubsistencia de individuos enfrentados entre sí.

Dicho de otro modo: el Derecho (o la ley) Natural clásico dice de un orden divino que el hombre participa y realiza; el Derecho Natural moderno, en cambio, es una afirmación de lo específicamente humano, de lo humano inmanente, no trascendente ${ }^{48}$. Si la Iglesia fue en el medioevo (lo será siempre) la custodia de la ley natural, en la Modernidad lo será el Estado, que no es más que la voluntad de los individuos que forman la colectividad, lo que importa la primacía, en definitiva, de la ley positiva. Nuevamente, por otro camino, se comprueba que el Estado es hijo y agente, a la vez, de la secularización de la política ${ }^{49}$.

Con todo lo que podamos observar de acertado en el fino examen de Strauss -que hemos visto comprobado con otros testimonios-, hay un punto que debe corregirse: la superioridad del estado de naturaleza es, para todos, derrotable por la sociedad civil o Estado; esa exaltada apreciación de lo natural es solamente teórica (diría que hasta retórica), pues el tránsito al Estado es prácticamente irrenunciable, por necesario. Bien dice Brett que una de las señas clave de la ley natural en la Modernidad temprana es la generalizada comprensión de la "insostenibilidad de una condición de igual libertad natural gobernada sólo por la ley natural" 50 . Esto es, la fundación de los Estados es siempre necesaria, lo que tiene también enormes efectos. La ley natural, por comenzar, también es derrotable: para los contractualis-

48 En Rousseau, lo natural es ambiguo, contradictorio. Por caso, en las páginas finales del Emilio, escribe con ecos luteranos y calvinistas: "Pero las leyes eternas de la naturaleza y del orden existen. Actúan como una ley positiva para los sabios; ellas están escritas en lo más profundo de su corazón por la conciencia y la razón; es a ellas a las que debe esclavizarse para ser libre; y no hay más esclavo que el que hace el mal, pues siempre lo hace a pesar de sí mismo. La libertad no está en ninguna forma de gobierno, está en el corazón del hombre libre, la lleva consigo a todas partes. El hombre vil lleva a todas partes la servidumbre. El uno sería esclavo en Ginebra y el otro libre en París". Rousseau, J. J. (1762). "Émile ou de l'éducation". En Euvres. VIII y IX. Paris. Lequien, 447. En el Contrato Social asevera que lo natural es algo instintivo, grabado en el corazón de los hombres, no en piedra o bronce (II, XII), pero lo social de lo natural no nace sino de la voluntad que hace el contrato (I, I). Rousseau, J. J. (1762). "Du contrat social ou Principes de Droit Politique”. En Euvres. V. Paris. Lequien, 98 y 158.

49 Haakonssen, K. (1996). Natural law and moral philosophy. From Grotius to the Scottish Enlightenment. Cambridge. Cambridge University Press, 31: "Hobbes, al igual que Grotius, trabajan prima facie bajo una ambigüedad. Por un lado, ambos escriben desde un punto de vista teísta según el cual la vida y la moral es parte de la dispensa divina. Por otro lado, pretenden dar cuenta del aspecto moral de esta exención de tal manera que explique cómo las personas sin creencias teístas pueden tener una vida moral".

50 Brett, A. S. (2011). Changes of state. Nature and the limits of the city in early modern natural law. Ob. cit., 115. 
tas es nada más que un punto de partida inicial a superar por la ley positiva del soberano ${ }^{51}$.

Es cierto que la permanencia de resabios del estado de naturaleza en el Estado pactado podría significar que aquél es, en cierto modo, mejor, pero contra esto batalla la inevitabilidad del Estado pacticio (con todo lo lamentable que esto pueda significar a los románticos) y la superioridad de la ley positiva sobre la natural. La fuerza individual se derrota con la fuerza colectiva, pues aquélla es caótica y ésta es organizada; aquélla es ilegítima, está goza de plena legitimidad. Dejar la naturaleza es requisito indispensable para seguir con vida, pues el vivir humano exige la desnaturación de la vida ${ }^{52}$. Por eso la autoconservación individual, una vez constituido el Estado, permanece en el limbo, como un derecho ambiguo, que no puede ser negado (así Hobbes o Locke) pero tampoco admitido o reconocido (Rousseau y Kant). Lo que prueba, una vez más, que en el convencionalismo lo justo no puede ser natural ${ }^{53}$. La justicia es posterior a la naturaleza, la establece la voluntad humana colectiva, el Estado.

Este hecho, el que el estado de naturaleza sea precario y que el Estado civil se vuelva necesario, puede decirse de otro modo: en el corazón del Estado moderno está instalada la pugna entre la razón de Estado (la autosubsistencia del Estado) y la razón de los derechos (la autoconservación de los individuos), entre una Modernidad sólida y otra líquida. Si la primacía se concede a la razón de Estado, los individuos deben resignarse a respetar su voluntad, aunque les sea perjudicial o contravenga sus intereses. En cambio, si se privilegia la razón de los derechos, entonces el Estado queda sometido a los intereses y voluntades individuales convertidos en norma. En el primer caso, se garantiza un ordenamiento coercitivo; en el segundo,

51 Esto significa que la moralidad es también absorbida por el Estado, incluso en Locke que, en el Ensayo sobre el entendimiento humano, la ha sustraído al remitirla a su registro sociológico, la ley de la moda, que acaba siendo interpretada por la ley humana o civil. Segovia, J. F. (2014). "John Locke y la ley de la moda. De la teología a la sociología de la ley natural". Revista de Estudios Histórico-Jurídicos Nro. XXXVI, 467-479.

52 Rousseau, J. J. (1762). "Émile ou de l'éducation". Ob. cit., VIII, 458, dice que al querer "formar al hombre de la naturaleza, no se trata de convertirlo en un salvaje y relegarlo al fondo del bosque; sino que encerrado en el torbellino social, le sea suficiente no dejarse llevar ni por las pasiones ni las opiniones de los hombres; que vea por sus propios ojos y sienta por su corazón; que ninguna autoridad lo gobierne fuera de su propia razón”. El arte humano, escribe también Rousseau, debe ser lo suficientemente inteligente para "prevenir que el hombre social se convierta en completamente artificial" (IX, 121). La naturaleza no se conserva pero se transmuta o convierte, como afirma en el Contrato Social. Antes del pacto éramos libres y después de él seguiremos tan libres como éramos.

53 Strauss, L. (1953). Natural right and history. Ob. cit., 11. 
se avalan libertades que erosionan el ordenamiento y hacen sucumbir la coerción jurídica ${ }^{54}$.

Si la observación es correcta, en los momentos de Modernidad sólida, la dureza de la ley estatal quisiera borrar los recuerdos del hombre natural, domeñándolo y convirtiéndolo en otro hombre, en el ciudadano que pretendía Rousseau; y cuando esa ley se torna porosa y deja correr por sus grietas la fluidez de la vida, los intereses de los individuos y los grupos reinstalan en el seno del Estado líquido las pasiones del estado de naturaleza, el Emilio educado por Rousseau. Danilo Castellano ha dicho, en consecuencia, que el Estado moderno vive de esta contradicción que hace presente el estado de naturaleza en cualquier momento, institucionalizando un estado de guerra ${ }^{55}$.

\section{e. El estado de naturaleza y discontinuidad de la vida humana}

El contractualismo introduce la discontinuidad en la existencia humana: el contrato es como un nudo a mitad de una cuerda que divide la vida en un momento "pre" y un momento "post", entre lo "natural" y lo "artificial", entre lo "forzado" y lo "voluntario", lo "ilegítimo" y lo "legítimo". De esta manera, rompe con la observación aristotélica de la simultaneidad de lo social y lo político, de la continuidad de lo natural en lo social, estableciendo un anterior y un posterior en una cadena causal de la voluntad. Rompe también con otra constatación aristotélica, la de la naturalidad de la ciudad, poniendo en su lugar la artificialidad de lo posterior (el Estado), en contraste con la naturalidad de lo anterior (la existencia natural). Si la comunidad política no viene de la naturaleza, sino que es un artificio surgido de humanas convenciones, también lo será la autoridad o poder político; pues siendo éste inherente a aquélla, no puede haber una autoridad natural.

Pero hay más: mientras que la filosofía clásica entendía a la naturaleza como perfectiva del hombre (pues es la forma que tiende al fin del ser), en el convencionalismo moderno la naturaleza se convierte en un estadio denigrante de la vida humana, que entra en contradicción con los deseos/ pasiones de los hombres. Para Hobbes, la vida es imposible, una guerra a muerte; para Locke, es una amenaza permanente a los Derechos Naturales, en especial, la propiedad privada; según Rousseau, no existe la moralidad y el hombre se vuelve esclavo del poderoso; etc. En todo caso, siempre el

54 Los ejemplos de nuestros días, en todo el mundo, si se comparan con los de hace medio siglo, también en todo el mundo, bastan para probar lo dicho.

55 Castellano, D. (1993). La razionalità della politica. Ob. cit., 35, 139-140, 145, 147. 
problema primario es el hombre mismo, el hombre natural ${ }^{56}$. Lo natural es malo; el bien, si lo hay, supone la necesaria desnaturación de los hombres $^{57}$, es decir, la convencionalidad de la moral, del Derecho y la política. "Construir el espacio cívico", el espacio de la racionalidad compartida -se diría hoy-, importa la adopción de reglas convenidas por los hombres, no el seguimiento de las leyes naturales. Y esas reglas convenidas están en el pacto social.

\section{Referencias}

Bobbio, N. (1986). "El modelo iusnaturalista”. En Bobbio, N. y Bovero, M. Sociedad y Estado en la filosofía moderna. El modelo iusnaturalista y el modelo hegelianomarxiano. México. FCE, 13-145.

Brett, A. S. (2011). Changes of state. Nature and the limits of the city in early modern natural law. Princeton \& Oxford. Princeton University Press.

Caro, J. (2011). The origins of free people. New York \& London. Continuum.

Castellano, D. (2020). Introducción a la filosofía de la política. Breve manual. Madrid. Marcial Pons.

Castellano, D. (2016). Martín Lutero. El canto del gallo de la Modernidad. Madrid. Marcial Pons.

Castellano, D. (1993). La razionalità della politica. Napoli. Edizioni Scientifiche Italiane.

Dicus, A. (2015). “Some man' and the savage”. Prose Studies Nro. 37/2, 97-111.

Dunn, J. (1969). The political thought of John Locke. Cambridge. Cambridge University Press.

Gentile, F. (2001). El ordenamiento jurídico, entre la virtualidad y la realidad. Madrid. Marcial Pons.

Gentile, F. (1983). Intelligenza politica e ragion di Stato. Milano. Giuffrè.

Gierke, O. (1950). Natural law and the theory of society: 1500 to 1800. Cambridge. Cambridge University Press.

Gillespie, M. A. (2008). The theological origins of modernity. Chicago \& London. The University of Chicago Press.

Grotius, H. (1625). The rights of war and peace. Indianapolis. Liberty Fund (2005).

Gunn, J. A. W. (October-December 1968). "Interest Will Not Lie: a seventeenth-century political maxim". Journal of the History of Ideas Nro. 29/4, 551-564.

Haakonssen, K. (1996). Natural law and moral philosophy. From Grotius to the Scottish Enlightenment. Cambridge. Cambridge University Press.

Hazard, P. (1988). La crisis de la conciencia europea (1680-1715). Madrid. Alianza.

56 Pufendorf, S. (1673). On the Duty of Man and Citizen According to Natural Law. Ob. cit., II, 5, 6 [3]: "Ningún animal es más feroz que el hombre, ninguno más salvaje y propenso a los mayores vicios perturbadores de la paz de la sociedad".

57 Hobbes, Th. (1651). "Leviathan". Ob. cit., I, XIII: "Al hombre, que no haya sopesado bien estas cosas, puede parecer extraño que la naturaleza venga a disociar y haga a los hombres aptos para invadir y destruirse mutuamente [...]". 
Hirschman, A. O. (1977). Las pasiones y los intereses. México. FCE.

Hobbes, Th. (1651). "Leviathan". En Hobbes, Th. The works of Thomas Hobbes. III. London. John Bohn. 1839.

Hobbes, Th. (1642). "De cive". En Hobbes, Th. The works of Thomas Hobbes. II. London. John Bohn. 1839.

Hume, D. (1739). Tratado de la naturaleza humana. Madrid. Tecnos. 1992.

Kahn, V. A. (2004). Wayward contracts. The crisis of political obligation in England, 1640-1674. Princeton \& Oxford. Princeton U.P.

Lamprecht, S. P. (1940). "Hobbes and Hobbism". American Political Science Review Nro. 34/1, 31-53.

Locke, J. (1689). Two treatises of government. London. 1768.

Matteucci, N. (2010). "Contractualismo”. En Matteucci, N. El Estado moderno. Léxico y exploraciones. Madrid. Unión Editorial - Universidad Francisco Marroquín, 107-133.

Pufendorf, S. (1673). On the Duty of Man and Citizen According to Natural Law. Cambridge. Cambridge University Press. 2006.

Pufendorf, F. (1672). Le droit de la nature et des gens. Amsterdam. 1734.

Riley, P. (1982). Will and political legitimacy. A critical exposition of social contract theory in Hobbes, Locke, Rousseau, Kant, and Hegel. Cambridge. Harvard University Press.

Rousseau, J. J. (1762). "Du contrat social ou Principes de Droit Politique”. En EE vres. V. Paris. Lequien. 1821.

Rousseau, J. J. (1762). “Émile ou de l'éducation”. En CEuvres. VIII y IX. Paris. Lequien. 1821.

San Agustín (426). "La Ciudad de Dios“. En San Agustín. Obras. XVI y XVII. Madrid. BAC. 1958.

Segovia, J. F. (2016). “Lutero y los orígenes religiosos de la secularización”. En Ayuso, M. (Ed.). Consecuencias político-jurídicas del protestantismo. A los 500 años de Lutero. Madrid. Marcial Pons, 49-84.

Segovia, J. F. (2014). La ley natural en la telaraña de la razón. Ética, derecho y política en John Locke. Madrid. Marcial Pons.

Segovia, J. F. (2014). "John Locke y la ley de la moda. De la teología a la sociología de la ley natural”. Revista de Estudios Histórico-Jurídicos Nro. XXXVI, 467-479.

Simmons, A. J. (1995). On the edge of anarchy. Locke, consent, and the limits of society. Princeton. Princeton University Press.

Sternberger, D. (1992). "La vieja polémica acerca del origen de la dominación”. En Sternberger, D. Dominación y acuerdo. Barcelona. Gedisa, 29-41.

Strauss, L. (1953). Natural right and history. Chicago. University of Chicago Press.

Strauss, L. (October 1950). "On the spirit of Hobbes' political philosophy". Revue Internationale de Philosophie Nro. 4/14, 405-431.

Walzer, M. (August 1984). "Liberalism and the art of separation". Political Theory Nro. 12/3, 315-330.

Williams, R. (1644). The Bloudy Tenent, Of Persecution, For Cause of Conscience. London. J. Haddon. 1848.

Zuckert, M. P. (1994). Natural rights and the new republicanism. Princeton. Princeton University Press. 